\title{
Hematopoietic Stem Cell Transplantation: Evolution and Future
}

\section{Perspectives}

\section{Nicola Daniele and Francesco Zinno*}

Immunohematology Section, Tor Vergata University and CryoLab - Stem Cells Manipulation and Cryopreservation Laboratory, Rome, Italy

\section{Abstract}

Hematopoietic stem cell transplantation is commonly used to treat several oncohematologic disease. The critical importance of cell dose in the clinical outcome, after transplant, has motivated the need to develop techniques aimed at reducing cell losses and increasing reproducibility.

Moreover, it has been clearly demonstrated that T-cells in a graft are directly correlated to the risk of developing a life-threatening GvHD in allotransplanted patients. Different techniques have been employed for this purpose, including physical, immunological and combined immunological/physical methods with different results in terms of purity, recovery, and time consumption.

To find new methods of cell manipulation is on of the most ambitious challenges in the field of stem cell transplantation.

\section{Introduction}

In the last sixty years, hematopoietic stem cells transplantation (HSCT) has evolved from an investigational therapy to a clinical standard, often frontline therapy in several diseases.

Hematopoietic stem cells transplantation has been subjected to rapid development and evolution since its inception, through translation of discoveries in the basic and clinical aspect of immunology, oncology, and infectious diseases into the transplant clinic.

\section{Discussion}

Furthermore, the last 30 years have seen rapid advances in novel strategies to improve and control graft function after transplantation include sophisticated methods of graft engineering. All of these new strategies involve ex vivo manipulations of the cellular component, ranging from simple volume reduction or cryopreservation to complex procedures such as the selection, expansion, and genetic manipulation of specific cell populations [1-5].

Moreover, in the field of allogeneic transplantation, it is exploring the potential of "new" cell populations, like as immune modulator cells. In fact, immune modulator cells, such as regulatory $\mathrm{T}$ cells (Tregs) and mesenchymal stromal cells (MSCs) have shown chances in their ability to control Graft versus Host Disease (GvHD).

Although pioneering studies trying to correlate Treg cells numbers and the risk of GvHD brought controversial results, several authors have now reported a lower cumulative incidence of GvHD in patients receiving a graft containing higher Treg cells [6-8].

The protective effect of adoptively transferred Treg cells in the GvHD perhaps is the joined result of direct suppression of effector T cells in lymphoid organs as well as down-modulation of APC function with respect to presentation of alloantigens [9]

To date, there are more than 50 ongoing clinical trials with the application of Tregs cellular therapy. Certainly, progress in understanding Treg cells biology and the optimization of protocols of Treg cells manipulation will promote the translation of researchbased knowledge to the clinic [10].

On the other hand, significant clinical expectations have been associated with three functional aspects of MSCs: tissue repair, hematopoietic engraftment support and immune modulation. Among clinicians, there is enthusiasm for the application of MSCs to clinical cell therapy and tissue engineering. Therapeutic advances in MSC therapy that take advantage of their trophic and immunoregulatory functions can fulfil major unmet needs in tissue regeneration [1].

In the field of transplantation it is also necessary to highlight that clinicians are very interested now to expand as much as possible the source of donors.Although human leukocyte antigen (HLA)identical sibling donors are generally the preferred donor source since complications such as graft failure and Graft versus Host Disease increase according to the number of HLA disparities between donor and recipient, in most developed countries, less than $30 \%$ of patients undergoing HSCT have an HLA-identical sibling.

A wider application of allogeneic hematopoietic stem cell transplantation is limited by the availability of HLA matched related or unrelated donors provided from bone marrow volunteer registries.

It is important to highlight that most patients considered eligible for transplantation lack a HLA-matched sibling donor and, alternatively, at least have a potential HLA-haploidentical related donor mismatched for three loci. However, a major obstacle to threeloci-mismatched haploidentical transplantation is the HLA barrier, mainly in the direction of GvHD. Various approaches to prevent GvHD have been investigated and the future of the transplantation is to identify new approaches to graft engineering for haploidentical transplantation [11-14].

Grafts depleted of CD3+ and CD19+ cells have been used in allogeneic, particularly haploidentical stem cell transplantation for pediatric patients suffering from hematologic malignancies or solid tumors. Unfortunately, graft rejection was observed especially in patients undergoing massive $\mathrm{T}$ cell-depleted transplantation. To date, the depletion of $\alpha / \beta$ T lymphocytes from mobilized peripheral stem

${ }^{*}$ Corresponding Author: Dr. Francesco Zinno, Immunohematology Section, Tor Vergata University and CryoLab - Stem Cells Manipulation and Cryopreservation Laboratory, Rome, Italy; Tel: +39 06 9936.6574; E-mail: zinno@cryolab.it

Citation: Daniele N, Zinno F (2015) Hematopoietic Stem Cell Transplantation: Evolution and Future Perspectives. Int J Lab Med Res 1: 103. doi: http://dx.doi. org/10.15344/2455-4006/2015/103

Copyright: (c) 2015 Daniele et al. This is an open-access article distributed under the terms of the Creative Commons Attribution License, which permits unrestricted use, distribution, and reproduction in any medium, provided the original author and source are credited. 
cells of from bone marrow for allogeneic transplantation is the best clinical evolution of T-cell-depleted transplantation.

TIn 2007, Chaleff et al. described a method for the clinical largescale depletion of $\alpha / \beta$ T lymphocytes from mobilized peripheral stem cells for allogeneic transplantation, while retaining all other cells: stem cells, natural killer cells, and $\gamma / \delta$ cells. These "facilitating" cells might facilitate engraftment, exert GvL effects, and reduce the risk for infections.

This method involves the incubation of cells with a biotinylated anti- $\alpha / \beta \mathrm{T}$-cell $\mathrm{Ab}$ and subsequently with an anti-biotin $\mathrm{Ab}$ conjugated to magnetic microbeads. The depletion was then performed using a CliniMACS device. Although with the depletion of $\alpha / \beta \mathrm{T}$ lymphocytes we have an enrichment of $\gamma / \delta \mathrm{T}$ cells in the graft, in the future, we should combine their expansion in vitro in association with a depletion of $\alpha / \beta$ T cells in the graft in order to have an optimal number of $\gamma / \delta$ T cells for transplantation $[12,15]$

One of the main challenges in allogeneic transplantation, in particular in the haploidentical setting, is to conserve the graft versus leukemia effects on the one hand and prevent GvHD on the other.

Natural killer (NK) cell infusion may be a perfect tool to exert graftversus-leukemia/tumor effects since induction of graft-versus-host disease has not been observed so far. Various methods for the clinical large-scale isolation of NK cells from PBSCs have been described and the adoptive transfer of haploidentical purified NK cells has been performed in clinical protocols.

Moreover, recent and current approaches evaluated whether additional activation and/or expansion of NK cells in vitro or in vivo, for example, with cytokines, such as IL-2 and IL-15, can be an option in order to enhance GvL/T efficacy. Furthermore, the capacity to reduce risk for GvHD and early relapse of hematological malignant diseases and the potential to emend an unstable donor chimerism after stem cell transplantation are under clinical investigations $[11,16,17]$.

To date clinical research is focusing also on clinical applications of antigen-specific $\mathrm{T}$ cells. In fact, new immunotherapeutic strategies have evolved using isolated antigen-specific $\mathrm{T}$ cells to treat infectious complications after hematopoietic stem cell transplantation and solid organ transplantation as well as hematologic malignancies and solid tumors.

Adoptively transferred antigen-specific $\mathrm{T}$ cells have been shown to restore protective immunity and control established Epstein Barr virus (EBV), adenovirus (AdV) and human cytomegalovirus (HCMV) infection after hematopoietic stem cells transplantation.

Moreover, it has been shown that sustained $\mathrm{T}$ cell immunity requires both $\mathrm{CD} 4+\mathrm{T}$ helper cells and $\mathrm{CD} 8+$ cytotoxic $\mathrm{T}$ cells. Now the enrichment of clinical-scale antigen-specific CD4+ and CD8+ T cells after in vitro stimulation with their respective antigen is possible with the CliniMACS Cytokine Capture System (IFN-gamma) (MiltenyiBiotec, BergischGladbach, Germany).

Enriched antigen-specific T cells can be used for adoptive transfer either directly after separation or after a short cultivation/expansion period. First clinical data demonstrate the efficacy of adoptively transferred antigen-specific $\mathrm{T}$ cells generated with the CliniMACS Cytokine Capture System (IFN-gamma) [18-20].

It's important to emphasize that all these new strategies could not be developed without the flow cytometry. Flow cytometry plays a crucial role in the field of the hematopoietic stem cells transplantation also for accuracy of diagnosis of the disorders that are the most indications for transplantation, for evaluation of immune reconstitution post-transplant, for the monitoring of chimerism in the haploidentical hematopoietic stem cells transplantation, and for indication of minimal residue disease [21].

In 1959, the first human bone marrow transplants gave a proof of concept that infusing bone marrow could provide hematological reconstitution in lethally irradiated patients with acute leukemia [22].

Following this pioneer work major progress has been achieved and nowadays hematopoietic stem cell transplant has saved the life of many patients worldwide.

Moreover, improvements in the outcome of hematopoietic stem cell transplant will depend on the clinical translation of many sophisticated advances in our knowledge of the cellular composition of the hematopoietic graft and the post-hematopoietic stem cell transplant cellular environment.

Selective allodepletion of the graft to remove cells most likely to cause GvHD and/or post HCT adoptive cellular therapy with T-regulatory cells or cytotoxic T-cells against tumor associate antigens are examples of strategies that could favorably influence the separation of GvHD and GvT and lead to improved survival outcomes [21].

Another emerging strategy for the prevention of Graft versus Host Disease is therapy targeting B cells. B cells have been implicated in the pathogenesis of GvHD. The effect of rituximab on chronic GvHD has been studied and is now being explored in the prevention of acute GvHD. Rituximab is a chimeric monoclonal antibody targeted against CD20+ B lymphocytes [23,24].

Finally, understanding of the molecular mechanism involved in controlling expression of chemokine and their receptors in GvHD may provide efficient strategies to manage of disease. However, little is known about such mechanisms. Most studies report that the conditioning regime are a initial signal to trigger production of cytokines (such as TNF- $\alpha$, IFN- $\gamma$, IL-1, IL-2) and, consequently, up regulation of chemokine receptors and their ligands. In some cases, blockade of a interleukinmay could provide a therapeutic option. For example, although patients with GvHD have elevated serum levels of IL10, whether its role is protective or pathogenic remains unclear. A study of Abraham S. et colleaguesdemonstrated for the first time, a direct role for IL-10 in driving GvHD pathogenesis. This clinical study indicated that blockade of IL-10 may provide a therapeutic option. Moreover, the data from the recent literature in this fieldsuggest that chemokines and their receptors represent promising molecules to be explored as therapeutic targets to modulate GvHD. Future research will reveal additional details surrounding the efficiency of these therapeutic strategies in the control of the inflammatory responses that are associated with GvHD [25-27].

\section{Competing Interests}

The authors declare that they have no competing interests exits.

\section{Author Contributions}

Nicola Daniele, contributed in drafting the manuscript. Francesco Zinno, contributed in drafting and reviewing the manuscript. 
Citation: Daniele N, Zinno F (2015) Hematopoietic Stem Cell Transplantation: Evolution and Future Perspectives. Int J Lab Med Res 1: 103. doi: http://dx.doi. org/10.15344/2455-4006/2015/103

Page 3 of 3

\section{References}

1. Tolar J, Hippen KL, Blazar BR (2009) Immune regulatory cells in umbilica cord blood: $\mathrm{T}$ regulatory cells and mesenchymal stromal cells. $\mathrm{Br} \mathrm{J}$ Haematol 147: 200-206.

2. Read EJ (1996) Quality assurance for cell processing: no more blind faith Transfusion 36: 1-4.

3. LeMaistre CF, Loberiza FR Jr (2005) What is quality in a transplant program? Biol Blood Marrow Transplant 11: 241-246.

4. Caunday O, Bensoussan D, Decot V, Bordigoni P, Stoltz JF (2009) Regulatory aspects of cellular therapy product in Europe: JACIE accreditation in a processing facility. Biomed Mater Eng 19: 373-379.

5. Cutler C, Antin JH (2005) An overview of hematopoietic stem cell transplantation. Clin Chest Med 26: 517-527.

6. Cohen JL, Boyer O (2006) The role of CD4+CD25hi regulatory T cells in the physiopathogeny of graft-versus-host disease. Curr Opin Immunol 18: 580-585

7. Rezvani K, Mielke S, Ahmadzadeh M, Kilical Y, Savani BN, et al. (2006) High donor FOXP3-positive regulatory T-cell (Treg) content is associated with a low risk of GVHD following HLA-matched allogeneic SCT. Blood 108: 1291-1297.

8. Pabst $\mathrm{C}$, Schirutschke $\mathrm{H}$, Ehninger G, Bornhäuser M, Platzbecker U (2007) The graft content of donor T cells expressing gamma delta TCR+ and CD4+foxp3+ predicts the risk of acute graft versus host disease after transplantation of allogeneic peripheral blood stem cells from unrelated donors. Clin Cancer Res 13: 2916-2922.

9. Hoffmann P, Ermann J, Edinger M (2005) CD4+CD25+ regulatory T cells in hematopoietic stem cell transplantation. Curr Top Microbiol Immunol 293 : 265-285

10. Daniele N, Scerpa MC, Landi F, Caniglia M, Miele MJ, et al. (2011) T(reg) cells: collection, processing, storage and clinical use. Pathol Res Pract 207 209-215.

11. Handgretinger R (2012) New approaches to graft engineering for haploidentical bone marrow transplantation. Semin Oncol 39: 664-673.

12. Daniele N, Scerpa MC, Caniglia M, Bernardo ME, Rossi C, et al. (2012) Transplantation in the onco-hematology field: focus on the manipulation of $\alpha \beta$ and $\gamma \delta$ cells. Pathol Res Pract 208: 67-73.

13. Anasetti C, Etzioni R, Petersdorf EW, Martin PJ, Hansen JA (1995) Marrow transplantation from unrelated volunteer donors. Annu Rev Med 46: 169179 .

14. Kanda J, Chao NJ, Rizzieri DA (2010) Haploidentical transplantation for leukemia. Curr Oncol Rep 12: 292-301.

15. Chaleff S, Otto M, Barfield RC, Leimig T, lyengar R, et al. (2007) A largescale method for the selective depletion of alphabeta $T$ lymphocytes from PBSC for allogeneic transplantation. Cytotherapy 9: 746-754.

16. Passweg JR, KoehI U, Uharek L, Meyer-Monard S, Tichelli A (2006) Naturalkiller-cell-based treatment in haematopoietic stem-cell transplantation. Best Pract Res Clin Haematol 19: 811-824.

17. Curti A, Pandolfi S, Valzasina B, Aluigi M, Isidori A, et al. (2007) Modulation of tryptophan catabolism by human leukemic cells results in the conversion of CD25- into CD25+ T regulatory cells. Blood 109: 2871-2877.

18. Feuchtinger T, Matthes-Martin S, Richard C, Lion T, Fuhrer M, et al. (2006) Safe adoptive transfer of virus-specific T-cell immunity for the treatment of systemic adenovirus infection after allogeneic stem cell transplantation. $\mathrm{Br}$ J Haematol 134: 64-76.

19. Mackinnon S, Thomson K, Verfuerth S, Peggs K, Lowdell M (2008) Adoptive cellular therapy for cytomegalovirus infection following allogeneic stem cell transplantation using virus-specific T cells. Blood Cells Mol Dis 40: 63-67.

20. Dudley ME, Wunderlich JR, Robbins PF, Yang JC, Hwu P, et al. (2002) Cancer regression and autoimmunity in patients after clonal repopulation with antitumor lymphocytes. Science 298: 850-854.
21. Spitzer TR, Dey BR, Chen YB, Attar E, Ballen KK (2012) The expanding frontier of hematopoietic cell transplantation. Cytometry B Clin Cytom 82: 271-279.

22. THOMAS ED, LOCHTE HL Jr, LU WC, FERREBEE JW (1957) Intravenous infusion of bone marrow in patients receiving radiation and chemotherapy. N Engl J Med 257: 491-496.

23. Shimabukuro-Vornhagen A, Hallek MJ, Storb RF, von Bergwelt-Baildon MS (2009) The role of B cells in the pathogenesis of graft-versus-host disease. Blood 114: 4919-4927.

24. Arai S, Sahaf B, Narasimhan B, Chen GL, Jones CD, et al. (2012) Prophylactic rituximab after allogeneic transplantation decreases B-cell alloimmunity with low chronic GVHD incidence. Blood 119: 6145-6154.

25. Bouazzaoui A, Spacenko E, Mueller G, Miklos S, Huber E, et al. (2009) Chemokine and chemokine receptor expression analysis in target organs of acute graft-versus-host disease. Genes Immun 10: 687-701.

26. Castor MG, Pinho V, Teixeira MM (2012) The role of chemokines in mediating graft versus host disease: opportunities for novel therapeutics. Front Pharmacol 3: 23.

27. Abraham S, Choi JG, Ye C, Manjunath N, Shankar P (2015) IL-10 exacerbates xenogeneic GVHD by inducing massive human $T$ cell expansion. Clin Immunol 156: 58-64. 